\title{
Characterisation of Neem and Jatropha Curcas Oils and their Blends with Kerosene for Combustion in Liquid Bio Fuels Cooking Stoves
}

\author{
Adamu A. Shanono *, Ibraheem S. Diso and Isa Garba
}

Department of Mechanical Engineering, Bayero University Kano, Kano State, Nigeria

\begin{abstract}
The characterisation of raw vegetable oils of neem and jatropha curcas seeds was experimentally carried out in order to obtain requisite data for the design process of liquid bio fuels cooking stoves. Properties of nineteen vegetable oils/kerosene blends including the kerosene sample were also experimentally determined for the purpose of testing the designed and developed bio stoves that utilised these fuel/oils blends as fuels. Results of the characterisation revealed that the kinematic viscosity of jatropha oil $\left(57.6 \mathrm{~mm}^{2} / \mathrm{s}\right)$ was 36 times more than the viscosity of the kerosene sample $\left(1.6 \mathrm{~mm}^{2} / \mathrm{s}\right)$. On the other hand, the viscosity of neem oil $\left(62.6 \mathrm{~mm}^{2} / \mathrm{s}\right)$ was 39 times greater than that of the kerosene sample. In addition, the density of jatropha curcas oil $\left(860 \mathrm{~kg} / \mathrm{m}^{3}\right)$ was more than that of the kerosene $(760$ $\left.\mathrm{kg} / \mathrm{m}^{3}\right)$ by $13.16 \%$, while the density of neem oil $\left(890 \mathrm{~kg} / \mathrm{m}^{3}\right)$ exceeded that of kerosene sample by $17.11 \%$; all the tests were conducted at $30^{\circ} \mathrm{C}$. Meanwhile, the acid number values of jatropha $(1.2 \mathrm{mg} \mathrm{KOH} / \mathrm{g})$ and neem $(3.1 \mathrm{mg} \mathrm{KOH} / \mathrm{g})$ oils did not meet the ASTM D6751 acid number standard specification, and only jatropha curcas oil satisfied the DIN 51605 specification. Blending of the oils with kerosene ensured that all the kerosene/jatropha oil blends met the DIN 51605 specification, however only six kerosene/neem oil blends $(10 \%$ to $60 \%$ concentrations) satisfied the requirement. Moreover, among all the kerosene/oils blends, only the $10 \%$ and $20 \%$ jatropha and $10 \%$ neem oils concentrations in the blends met the ASTM D6751 standard acid number specification.
\end{abstract}

Keywords: Biomass, Vegetable Oil, Standard Specification, Test Method, Wick Stove.

\section{INTRODUCTION}

Biomass refers to recently living organisms, most often referring to plants or plant-derived materials. Bio fuel (on the other hand) is a fuel that is produced through contemporary biological processes, such as agriculture and anaerobic digestion, rather than a fuel produced by geological processes such as those involved in the formation of fossil fuels, such as coal and petroleum from prehistoric biological matter [1]. Solid and liquid bio fuels are derived from combustible biomass material. For example: garden waste, firewood, and agricultural waste products are solid bio fuels; liquid bio fuels meanwhile are obtained by extracting oil from plants or their seeds that naturally produce oil. Some of these are palm, coconut, jatropha, neem and mahogany trees. Others include cottonseeds, moringa, corn, groundnuts and sesame seeds.

Biodiesel is a form of bio fuel that is produced from vegetable oils extracted from plants or their seeds or from fats through transesterification reaction. It is a liquid similar in composition to mineral diesel and its chemical name is Fatty Acid Methyl Ester (FAME). Vegetable oils refer to raw untransesterified; Straight Vegetable Oil (SV0), Pure Plant Oil (PPO), Used

${ }^{*}$ Address correspondence to this author at the Department of Mechanical Engineering, Bayero University Kano, Kano State, Nigeria;

Tel: +2348066038135; E-mail: aashanono@yahoo.com
Vegetable Oil (UVO), Waste Vegetable Oil (WVO), or Used Cooking Oil (UCO) [2]. There are a lot of misconceptions on the meanings of biomass, bio fuel, and biodiesel. For example, oftentimes raw vegetable oils, which are liquid bio fuels, are wrongly referred to as biodiesel. In order to correct the wrong interpretation of Biodiesel, the National Renewable Energy Laboratory (NREL) [2] of the United States Department of Energy specifically stated that; "the word Biodiesel refers to the pure fuel 'B100' that meets the specific biodiesel definition and standards approved by ASTM International. A number following the ' $B$ ' indicates the percentage of biodiesel in a gallon of fuel, where the remainder of the gallon can be No.1 or No.2 diesel, kerosene, jet A, JP8, heating oil, or any other distillate". Thus, "raw or refined vegetable oil, or recycled grease that have not been processed into biodiesel are not biodiesel and should be avoided" [2].

NREL [2] further indicated that the definition of biodiesel within ASTM D6751 describes long chain fatty acid esters from vegetable or animal fats that contain only one alcohol molecule on one ester linkage. Raw or refined vegetable oils contain three ester linkages and are therefore not legally biodiesel. (Therefore) the definition of biodiesel contained in ASTM D6751, along with the physical and chemical properly limits, eliminates certain 'bio fuels' that have been incorrectly called biodiesel in the past. The raw vegetable oil or animal fat feedstock, partially reacted oils or fats, coal slurries, or any other "biologically 
derived" fuels not meeting the definition and requirements for B100 listed in ASTM D6751 - 03 are not biodiesel and should not be confused with biodiesel. The definition of biodiesel thus is; Biodiesel, noun, a fuel comprised of mono-alkyl esters of long chain fatty acids derived from vegetable oils or animal fats, designated B100 [2].

In defining what "Biodiesel Blend" means, the National Conference on Weights and Measures (NCWM) [3], which was supported by the National Institute of Standards and Technology (NIST) affirmed that, "Biodiesel Blend" is a fuel comprised of a blend of biodiesel fuel (transesterified vegetable oils and other feedstock) with petroleum based diesel fuel, designated BXX. In the abbreviation BXX (e.g. B20), biodiesel blends are indicated by a "B" with a number following the $B$ (e.g. 20) that represents the volume percentage of biodiesel fuel in the blend. B100 biodiesel intended for blending with diesel fuel shall meet the latest version of ASTM D6751, "Standard Specification for Biodiesel Fuel (B100) Blend Stock for Distillate Fuels" [3].

Blin et al. [4] noted that there are three main biodiesel standards: the American Standard ASTM D6751, the European Standard EN 14214, and the Brazilian Standard ANP No. 7/2008, the last (was) largely based on the two others.

The most significant aspect of this study was the realisation that there was no ASTM, EN, and ANP standard specification for the testing and characterisation of vegetable oils, which were to be used directly as fuels in engines, or in capillary fed wick lamps or cooking stoves. Similarly, there was no any standard specification for their blending with fossil solvents (diesel, kerosene, or gasoline). [4] noted that Remmele and Thuneke [5] indicated that test methods have not been established for vegetable oils, but for diesel fuels or for biodiesel. Their repeatability and applicability to vegetable oils need to be evaluated. Blin et al. [4] added that there has been no generic standard for SVO, whatever the nature of the oil. However, due to the growing interest on the use of vegetable oils as fuels, the German Deutsche Institut für Normung (DIN) proposed a specific quality prestandard for rapeseed oil - DIN 51605, and DIN 51623 for vegetable oil compatible combustion engines. (Meanwhile), these test methods have some limitations. (For instance,) DIN 51605 was specific to rapeseed oil and (it) is too drastic and involves analytical tools that are difficult to set in place in agricultural zones, especially in developing countries. It is also based on analytical methods used in the petroleum sector that require many resources and technical skill [6].

Notwithstanding the absence of ASTM, EN, and ANP specifications for vegetable oils, research on the feasibility of using raw vegetable oils as fuels has not abated. "Some researchers use simple analytical methods, partially based on those recommended for the Standardisation of Edible Vegetable Oils" [4]. Most researchers however, based on information gathered from publications in international journals, use the standard test methods for Biodiesel B100 to characterise the raw vegetable oils in their research studies regardless of the challenges this might pose. These researchers belong to this category of individuals.

The second significant aspect of this work was that almost all the test methods established by the three standard organisations mentioned above, especially on density and viscosity based the characterisation of fuels at $15^{\circ} \mathrm{C}$ and $38-40^{\circ} \mathrm{C}$ respectively. For example; the kinematic viscosities of fourteen vegetable oils at $38^{\circ} \mathrm{C}$ reported by Srivastava and Prasad [7] range from 27.2 to $53.6 \mathrm{~mm}^{2} / \mathrm{s}$. The DIN 51605 [8] standard specifications for density at $15^{\circ} \mathrm{C}$ and kinematic viscosity at $40^{\circ} \mathrm{C}$ for rapeseed oil are $900-925 \mathrm{~kg} / \mathrm{m}^{3}$ and $36 \mathrm{~mm}^{2} / \mathrm{s}$ respectively. In addition, ASTM D6751 limits for density at $15^{\circ} \mathrm{C}$ and kinematic viscosity at $40^{\circ} \mathrm{C}$ for Biodiesel B100 are $860-900 \mathrm{~kg} / \mathrm{m}^{3}$ and 1.9-6.0 $\mathrm{mm}^{2} / \mathrm{s}$ respectively [2]. However, all the test fuels in this study were characterised at $30^{\circ} \mathrm{C}$. The reason being that $30^{\circ} \mathrm{C}$ was the average observed, but undocumented ambient temperature in the researchers' home kitchens.

Srivastava and Prasad [7] noted that vegetable oils comprise 90 to $98 \%$ triglycerides and small amounts of mono- and diglycerides. They added that considerable efforts have been made to develop vegetable oil derivatives that approximate the properties and performance of the hydrocarbon-based diesel fuels. They concurred that the problems with substituting triglycerides for diesel fuels are mostly associated with their high viscosities, low volatilities (high flash points) and polyunsaturated character. In addition, the volumetric heating values of these oils were in the range of 39 to $40 \mathrm{MJ} / \mathrm{kg}$, which were low compared to diesel fuel. 
These properties of vegetable oils that hinder their direct use in diesel engines, also to a large extent made their utilisation undiluted in capillary fed cooking stoves virtually impossible. The density of jatropha curcas oil as reported by Okullo et al. [9] was $910 \pm 2.64$ $\mathrm{kg} / \mathrm{m}^{3}$. Meanwhile, the ASTM standard specifications of kinematic viscosity at $40^{\circ} \mathrm{C}$ and density at $15^{\circ} \mathrm{C}$ for kerosene are $1.0-1.9 \mathrm{~mm}^{2} / \mathrm{s}$ and $740-790 \mathrm{~kg} / \mathrm{m}^{3}$ respectively $[10,11]$. On the other hand, the ASTM D6751 flash point specification for Biodiesel B100 is $130^{\circ} \mathrm{C}$ (minimum) [2], and the DIN 51605 flash point specification for rapeseed oil is $101^{\circ} \mathrm{C}$ (minimum) [8].

Soetaredjo et al. [12] reported high acid number value of $19.6283 \mathrm{mg} \mathrm{KOH} / \mathrm{g}$ for neem oil at $30^{\circ} \mathrm{C}$, while Adebowale and Adedire [13] and Okullo et al. [9] reported acid values of 4.24 and $3.38 \pm 0.23 \mathrm{mg} \mathrm{KOH} / \mathrm{g}$ respectively for jatropha curcas seed oil. Meanwhile, the DIN 51605 acid value limit for rapeseed oil is 2.0 (max.) $\mathrm{mg} \mathrm{KOH} / \mathrm{g} \mathrm{[8],} \mathrm{and} \mathrm{the} \mathrm{ASTM} \mathrm{D6751} \mathrm{limit} \mathrm{for}$ Biodiesel $\mathrm{B} 100$ is 0.50 (max.) $\mathrm{mg} \mathrm{KOH} / \mathrm{g}$ [2]. Furthermore, Yadav and Jha [14] carried out a case study on bio fuel stove technology that utilised raw vegetable oil of jatropha seeds as fuel in a modified capillary fed kerosene cooking stove. The jatropha oil utilised in their tests had viscosity of $75.7 \mathrm{~mm}^{2} / \mathrm{s}$, which was much more than the viscosity of the kerosene sample used $\left(2.2 \mathrm{~mm}^{2} / \mathrm{s}\right)$.

The high viscosities, low volatilities (high flash points) and polyunsaturated character of vegetable oils can be changed in at least four ways, namely; pyrolysis, micro emulsification, dilution (blending) and transesterification [7]. Consequently, in order to ensure good performance of vegetable oils when used as substitutes to kerosene in cooking stoves, it will entail blending the oils with a fuel that is less viscous and with a very low flash point in order to improve these properties for effective combustion. Blending of the oils with a fuel that has very low acid value could also reduce their acidity. As a start, blending with kerosene was the preferred option since it was the most commonly used fuel for cooking in capillary fed wick stoves by middle level income earners in third world countries (especially Nigeria).

The characterisation of neem and jatropha curcas oils and their blends with kerosene became necessary in order to obtain requisite data for the design process of liquid bio fuels cooking stoves, and to analyse performance and emission characteristics of the stoves when combusting these fuel oils blends. Analyses of the performance and emission characteristics of the stoves will be treated in a different article.
Notwithstanding the fact that there was no known Standard Specification for characterisation of raw vegetable oils, or for blending with kerosene (or fossil fuels) other than the German DIN Standard Methods specifically for testing of rapeseed oil and vegetable oil compatible combustion engines fuels, blending of neem and jatropha oils with kerosene were carried out in this study. Suffice it to say that the nomenclature $B X X$, as defined by ASTM refers to the volume percentage $(X X)$ of biodiesel fuel $(B)$ in a blend with petroleum based diesel fuel or other fossil solvents, the nomenclatures BJXX and BNXX were adopted. However, the alphabet B refers to a 'BLEND' (and not Biodiesel Fuel) of either raw Jatropha oil 'J' or Neem oil ' $N$ ' with kerosene (blend of raw vegetable oil and any fossil solvent). $K$ denotes kerosene, and $X X$ refers to the volume percentage of the oils in the blends. Thus BN10, BN20, BN30, BN40, BN50, BN60, BN70, BN80, $\mathrm{BN} 90$, and $\mathrm{BJ} 10, \mathrm{BJ} 20, \mathrm{BJ} 30, \mathrm{BJ} 40, \mathrm{BJ} 50, \mathrm{BJ} 60$, $B J 70, B J 80, B J 90$ are the neem oil/kerosene, and jatropha oil/kerosene blends that have been investigated. Meanwhile, N100 and J100 denote raw undiluted neem oil and jatropha oil respectively, and K100 denotes undiluted kerosene fuel. These fuel/oils were also investigated.

\section{MATERIALS AND METHODS}

\subsection{Experimental Materials}

The Jatropha seeds utilised in this study were collected from farms' boundaries and bushes of Shanono town. Shanono is the headquarters of Shanono Local Government Area of Kano State NIGERIA. It lies between latitude $11^{\circ} 57^{\prime} 49^{\prime \prime}$ North to $12^{\circ} 16^{\prime \prime}$ North and longitude $7^{\circ} 51^{\prime} 47^{\prime \prime}$ East to $8^{\circ} 5^{\prime} 23^{\prime \prime}$ East. It has an area of approximately $679 \mathrm{~km}^{2}$ and share the same postal code of 704 with Kabo, Gwarzo and Rogo Local Government Areas of Kano State [15]. Shanono local government had a population of 139,128 in the 2006 National Census (Federal Republic of Nigeria Official Gazette No. 2, 2009) [16]. Figure 1 shows a typical farm demarcated with jatropha curcas trees in order to keep away animals (cows, goats and sheep) from the crops.

The oil was extracted from the jatropha seeds and refined by the National Research Institute for Chemical Technology (NARICT) Zaria, Kaduna State - Nigeria. NARICT also supplied the refined neem oil and the reference kerosene. In addition, the institute blended the kerosene with jatropha oil, and the kerosene with neem oil. Altogether, 21 test fuel samples made up of 
kerosene, jatropha oil, neem oil and the blends were characterised in this study. Figure 2 shows the 21 test fuel samples in plastic containers.

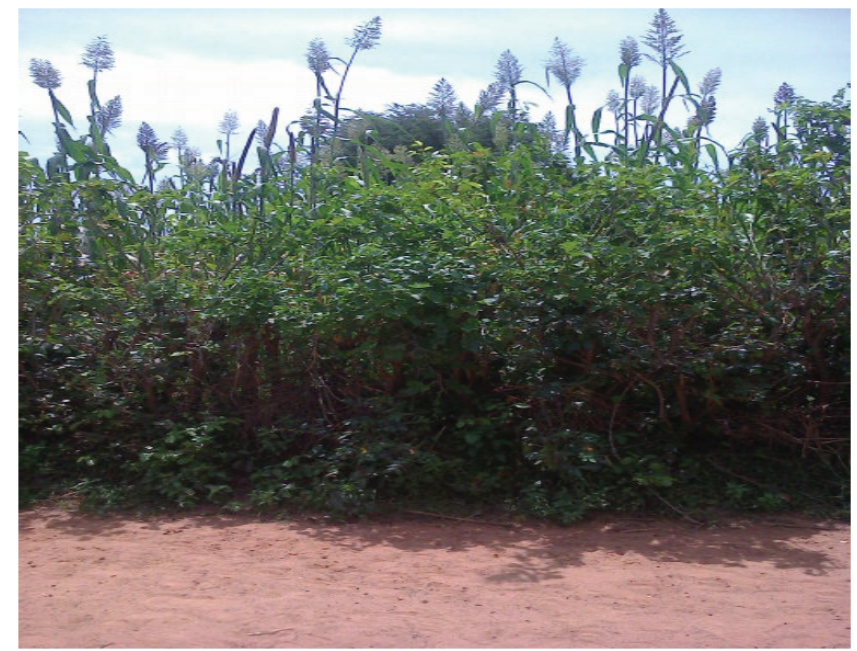

Figure 1: Jatropha Curcas Trees Planted by Farmers as Shield to Food Crops against Animals in a Farmland at Shanono Town, Kano - Nigeria.

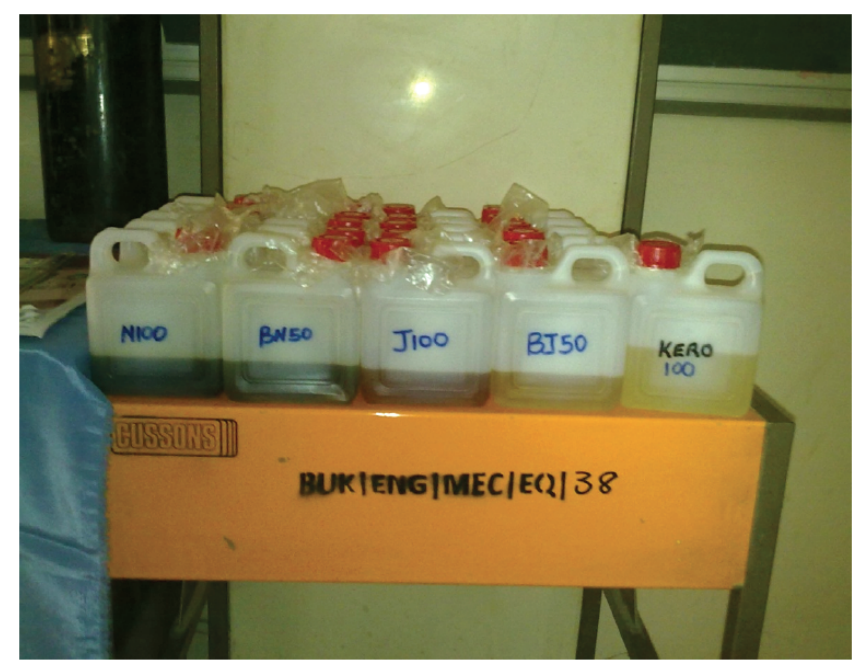

Figure 2: Twenty-One Test Fuel Samples.

\subsection{Tests Methods}

The thermal, physical and chemical properties of the test fuel samples namely; flash point temperatures, specific heats, densities, kinematic viscosities and, surface tension and acid number values were determined experimentally in conjunction with NARICT Zaria. The methodology employed complied with that of the NIST, meanwhile the ASTM test methods for biodiesel B100 were followed in the characterisation of the fuel samples. However, the calorific and thermal conductivity values of the fuel samples were determined at the Thermo - Fluids Laboratory of the Department of Mechanical Engineering, Bayero
University Kano - Nigeria vide the IP 12/73 standard test method (BS 7420:1991) and the Thermal Conductivity of Liquids and Gases Unit H470 - P.A. HILTON test method respectively.

Figure 3 shows the calorific value experimental test set up. The bomb calorimeter set with a Beckman thermometer, oxygen charging equipment (valves, gauges, filling tube and fittings), two litres water jar, four litres distilled water in plastic container, ignition wire, firing cotton and benzoic acid make up the experimental setup. The digital METTLER weight measuring equipment with a syringe and the test fuels crucibles are shown in Figure 4.

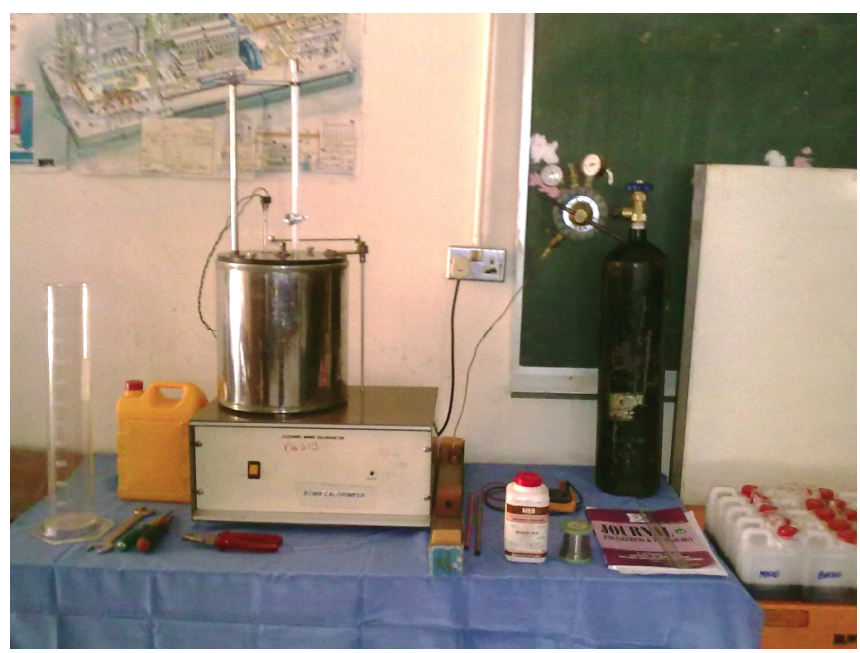

Figure 3: Calorific Value Experimental Set Up.

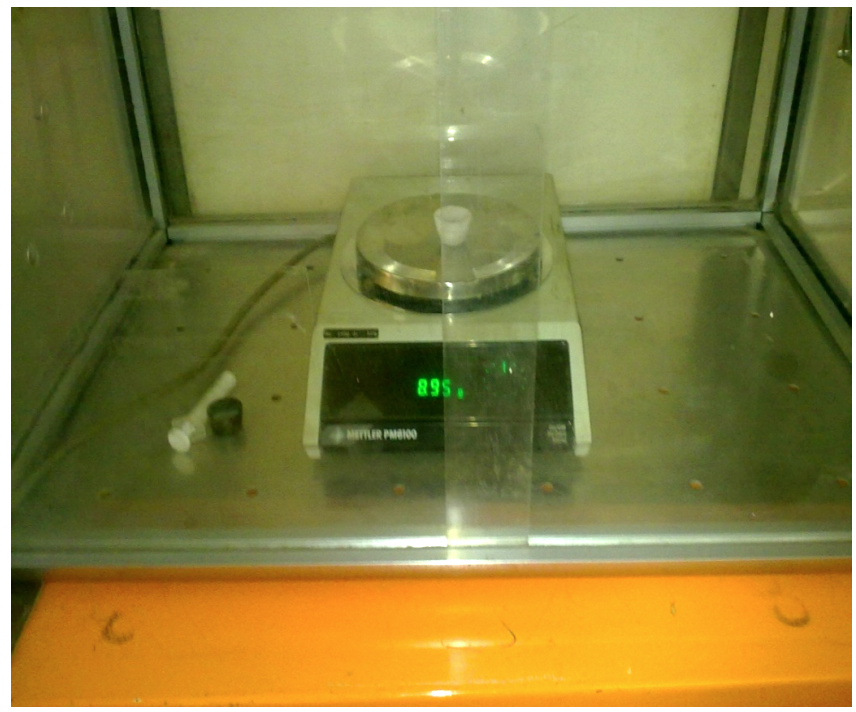

Figure 4: The METTLER PM6100 Digital Weight Measuring Instrument.

The thermal conductivity test experimental set up is shown in Figure 5. The thermal conductivity unit connected to the plug/jacket assembly with water 
inlet/outlet, and fluid charging connection with vent make up the experimental setup.

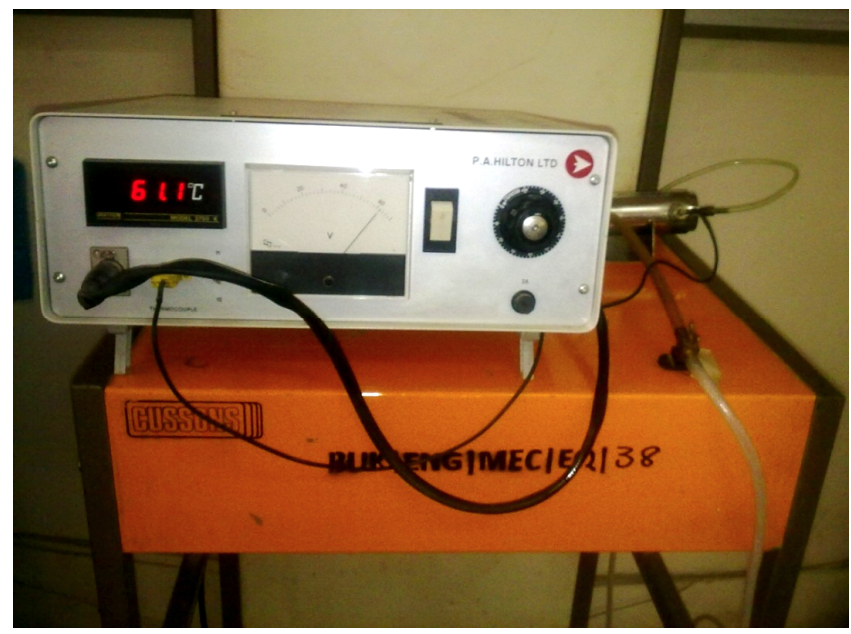

Figure 5: Thermal Conductivity Test Set - Up.

The justification for characterising the kerosene fuel sample based on the ASTM D6751 standard test method lies in the definition of Biodiesel B100 nomenclature by the NREL [2]. The definition suggests that ASTM D6751 covers the blending of B100 and Kerosene as earlier stated. In view of the definition of the B100 nomenclature and the meaning of alphabet "B" by [2], the nomenclatures $\mathrm{J}, \mathrm{N}, \mathrm{K}, \mathrm{BJ}$ and $\mathrm{BN}$ used in this study specifically, have been defined. Of particular interest is the nomenclature " $B$ ", which in this research work refers to a "BLEND" of vegetable oil and kerosene as earlier indicated.

\section{RESULTS AND DISCUSSION}

The main aim of blending kerosene with jatropha oil and neem oil separately into various blends, was to reduce the densities and viscosities of the oils, while also significantly reducing the flash points of the oils. Any variation in the density of a fluid under capillary effect and in a small diameter tube of uniform crosssectional area has direct impact on its surface tension assuming other parameters are constant, therefore the surface tensions of the test fuels were not be analysed. In addition, blending of the oils with kerosene increased their higher calorific values while at the same time reducing their acidity. Meanwhile, specific heats of the test fuels were analysed as components or part of their heat capacities.

\subsection{Physical Properties}

Figures 6 and 7 show the densities of the kerosene/jatropha oil and kerosene/neem oil blends.
From the figures, the density of $\mathrm{J} 100$ at $30^{\circ} \mathrm{C}(860$ $\left.\mathrm{kg} / \mathrm{m}^{3}\right)$ was more than that of $\mathrm{K} 100$ also at $30^{\circ} \mathrm{C}(760$ $\mathrm{kg} / \mathrm{m}^{3}$ ) by $13.16 \%$, while the density of $\mathrm{N} 100$ at $30^{\circ} \mathrm{C}$ $\left(890 \mathrm{~kg} / \mathrm{m}^{3}\right)$ exceeded that of $\mathrm{K} 100$ by $17.11 \%$. However, blending of K100 and the two oils separately significantly reduced their densities. The densities of BJ50 and BN50 reduced to $780 \mathrm{~kg} / \mathrm{m}^{3}$ and $850 \mathrm{~kg} / \mathrm{m}^{3}$ respectively. This was a reduction of $9.3 \%$ and $4.5 \%$ from the densities of $\mathrm{J} 100$ and N100. Density is an important determinant of the energy storage capability of a material, as the analysis on heat capacity showed (see section 3.2).

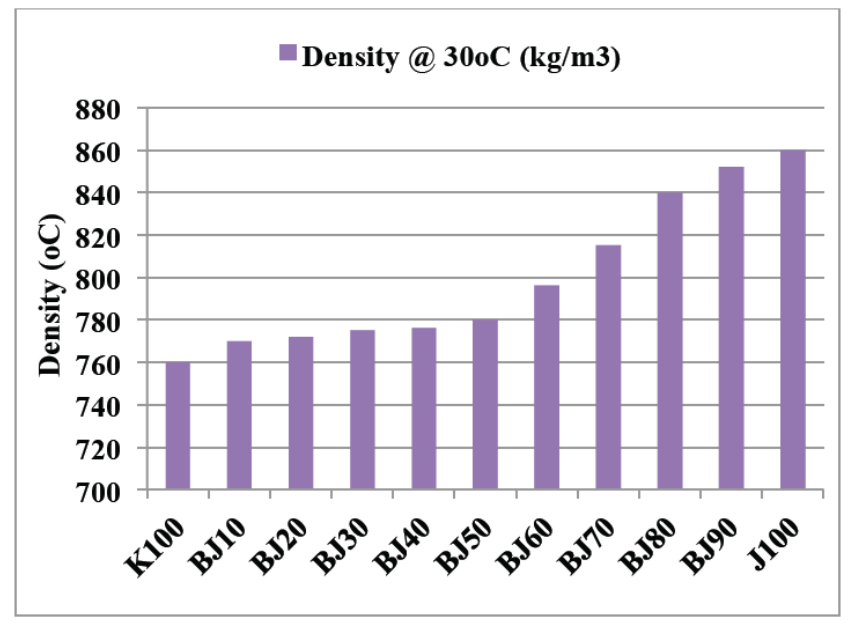

Figure 6: The Densities of Kerosene and Kerosene/Jatropha Oil Blends.

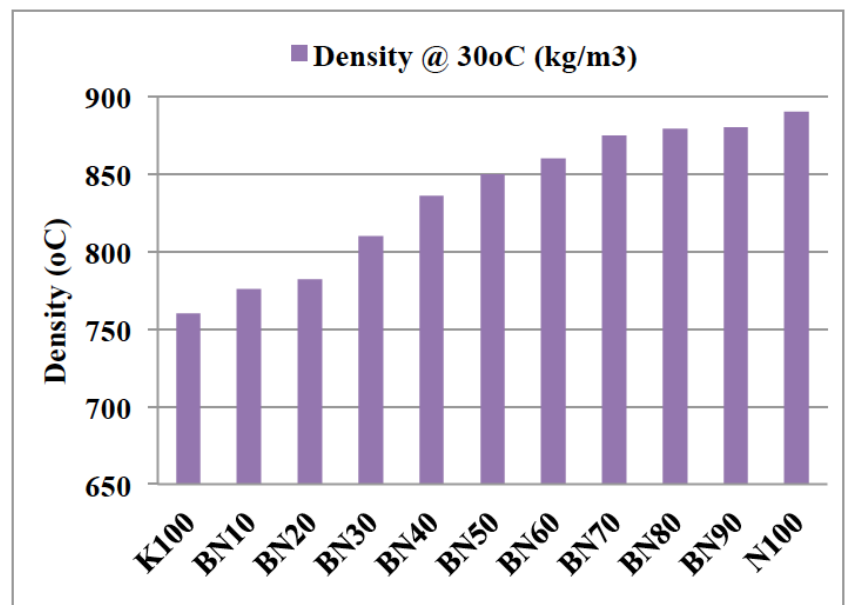

Figure 7: The Densities of Kerosene and Kerosene/Neem Oi Blends.

Figures 8 and 9 indicate the kinematic viscosities of Kerosene/Jatropha Oil and Kerosene/Neem Oil Blends. The kinematic viscosity of $\mathrm{J} 100$ was 36 times more than the viscosity of $\mathrm{K} 100$. On the other hand, the viscosity of $\mathrm{N} 100$ was 39 times greater than that of $\mathrm{K} 100$. The high viscosity of these oils is due to their 
large molecular mass and chemical structure [7]. However, blending of $\mathrm{K} 100$ and the two oils significantly reduced their viscosities. For example, the viscosity of BJ50 was $10.1 \mathrm{~mm}^{2} / \mathrm{s}$ and that of BN50 was $13.6 \mathrm{~mm}^{2} / \mathrm{s}$. These represent reductions of $82.5 \%$ and $78.3 \%$ in the two oils' viscosities. Lower values of viscosities are desired in order to ensure effective and sufficient fuel oil transport in the wick pipes of cooking stoves. The high values of viscosities of the oils must therefore be considered in designing the wick pipes and fuel oil tanks of the bio stoves, in order to achieve effective fuel oil transport from the tank to the tips of the wicks in the burner.

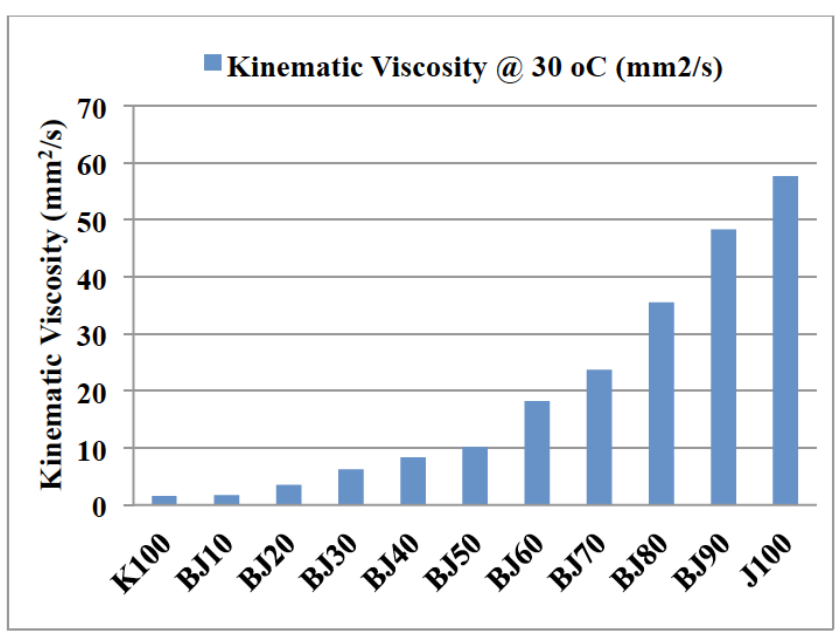

Figure 8: The Kinematic Viscosities of Kerosene and Kerosene/Jatropha Oil Blends.

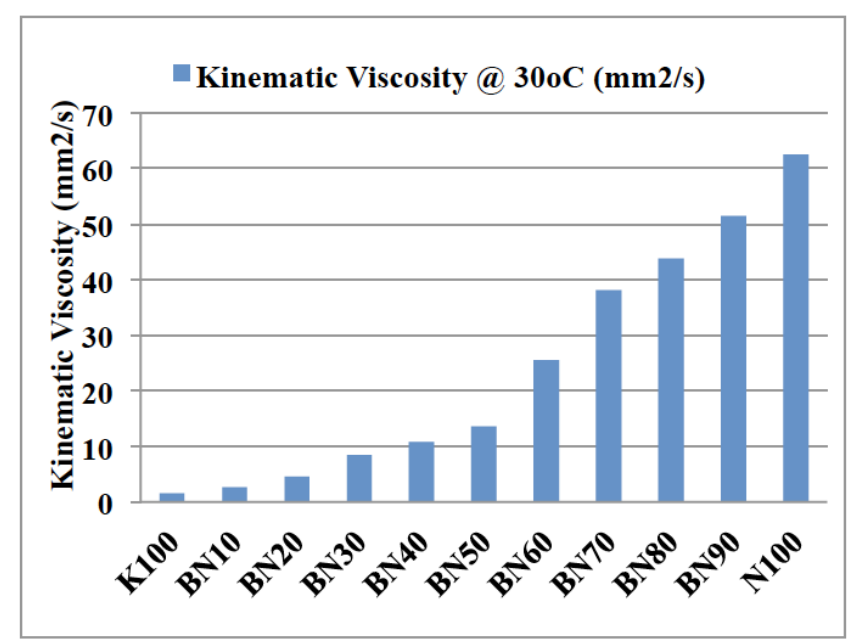

Figure 9: The Kinematic Viscosities of Kerosene and Kerosene/Neem Oil Blends.

\subsection{Thermal Properties}

Figures 10 and 11 indicate the flash points of kerosene, kerosene/jatropha oil and kerosene/neem oil blends. The flash points of K100, J100 and N100 were all above the minimum limits indicated in the ASTM [2] and DIN [8] standards specifications. There is the need to state that the minimum values for flash points of fuels designated in these standards are safety precautions against fire that could erupt from their storage in high temperature environment. Low volatility or high flash point is one of the characteristics of vegetable oils.

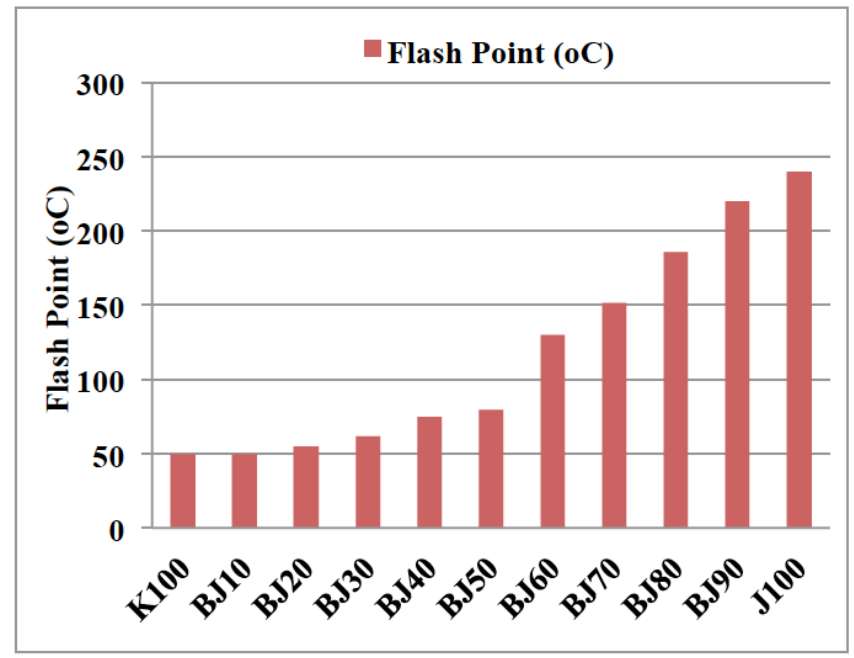

Figure 10: The Flash Points of Kerosene and Kerosene/Jatropha Oil Blends.

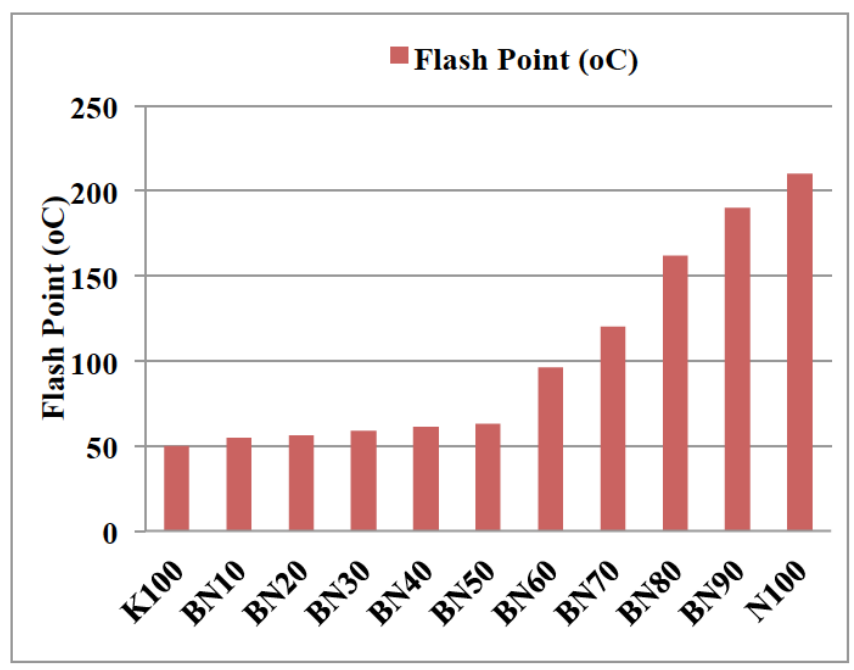

Figure 11: The Flash Points of Kerosene and Kerosene/Neem Oil Blends.

The volatility of $\mathrm{BJ} 50\left(80^{\circ} \mathrm{C}\right)$ compared to $\mathrm{J} 100$ $\left(240^{\circ} \mathrm{C}\right)$ increased by $66.7 \%$, while that of BN50 $\left(63^{\circ} \mathrm{C}\right)$ compared to $\mathrm{N} 100\left(210^{\circ} \mathrm{C}\right)$ increased by $70 \%$; these increases in volatilities (reduction in flash point temperatures) resulted from blending of the oils with K100. Though blending of the oils with kerosene significantly increased their volatile character, their flash points except for BJ10 were still higher than that 
of $\mathrm{K} 100$. This indicated that ignition of the wicks in the bio stoves containing higher blend ratios of jatropha and neem oils could be difficult. The use of quick start fuel (igniter) would therefore be necessary when igniting the wicks.

Calorific value represents the energy content of a fuel in terms of the amount of heat that will be released from its combustion. The two vegetable oils had lower energy contents than kerosene as depicted in Figures 12 and 13. The Higher Calorific Value (HCV) of K100 was $44.3 \mathrm{MJ} / \mathrm{kg}$, the value for BJ10 was $42.7 \mathrm{MJ} / \mathrm{kg}$, for BJ50 it was $41.9 \mathrm{MJ} / \mathrm{kg}$ and for J100 it was $39.5 \mathrm{MJ} / \mathrm{kg}$. Meanwhile the value for BN10 was $42.3 \mathrm{MJ} / \mathrm{kg}$, that of BN50 was $39.3 \mathrm{MJ} / \mathrm{kg}$ and for $\mathrm{N} 100$ it was $37.6 \mathrm{MJ} / \mathrm{kg}$. The heating value of $\mathrm{K} 100$ was greater than the heating value of $\mathrm{J} 100$ by $12.15 \%$ and much greater

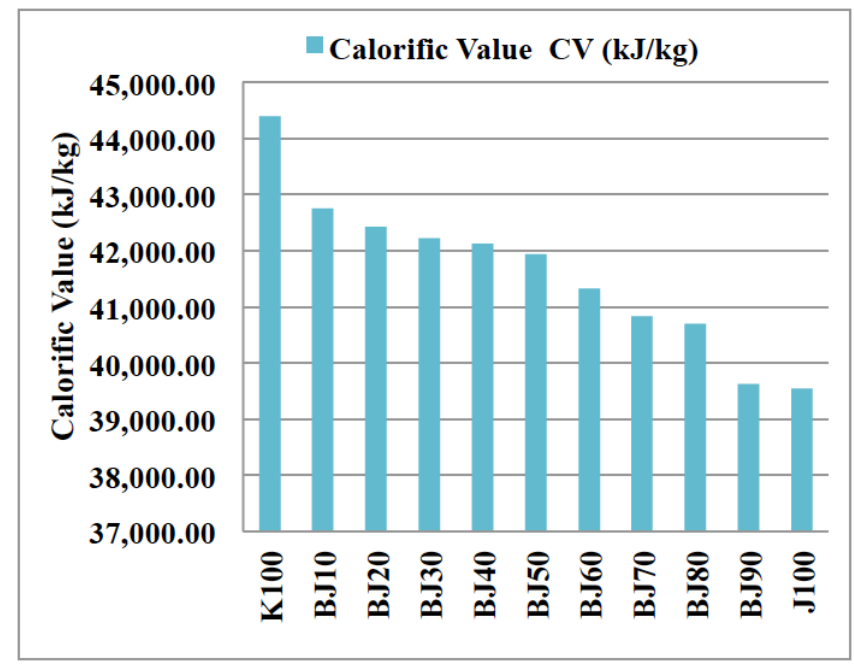

Figure 12: Higher Calorific Values of the Kerosene and Kerosene/Jatropha Oil Blends.

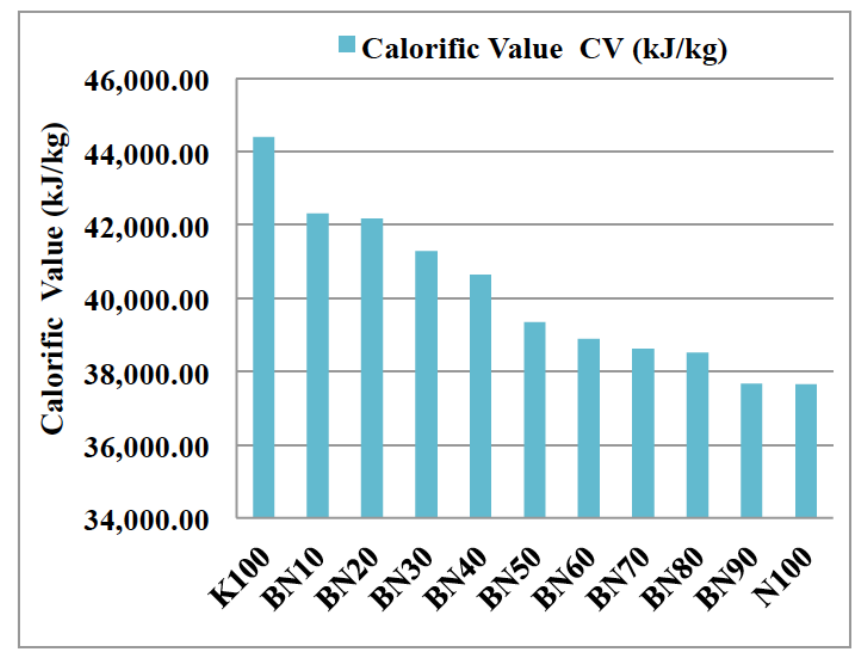

Figure 13: The Higher Calorific Values of Kerosene and Kerosene/Neem Oil Blends. than that of $\mathrm{N} 100$ by $17.8 \%$. The oils contain large amount of oxygen in their structure. "The presence of chemically bound oxygen in vegetable oils lowers their heating values by about $10 \%$ [7]". However, after blending of the oils with kerosene, their calorific values increased by $6.1 \%$ and $4.5 \%$ for BJ50 and BN50 respectively.

Thermal conductivity indicates how well (the test fuels) conducts heat [17]. It can be observed from figures 14 and 15 that heat conduction through the oils and their blends with kerosene would be better than through pure kerosene fuel.

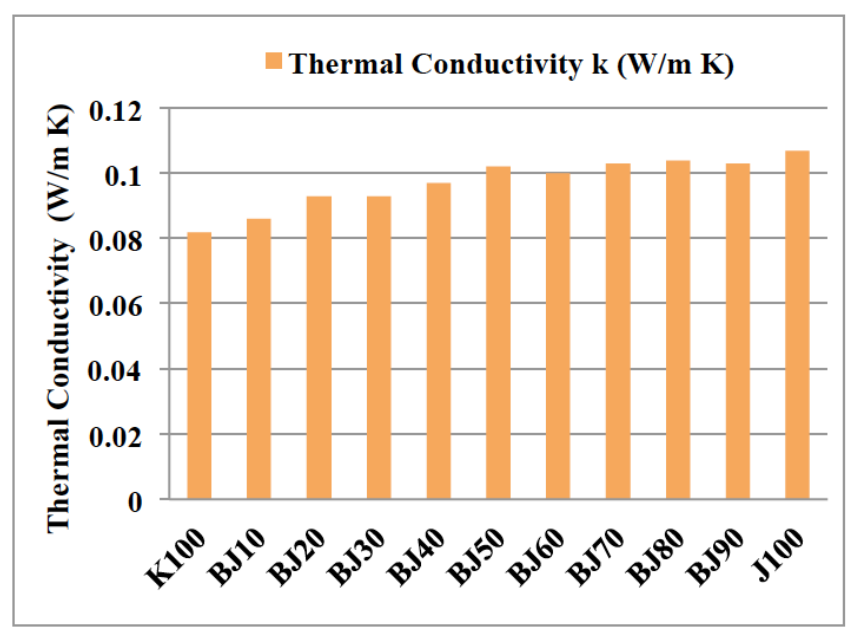

Figure 14: Thermal Conductivities of Kerosene and Kerosene/Jatropha Oil Blends.

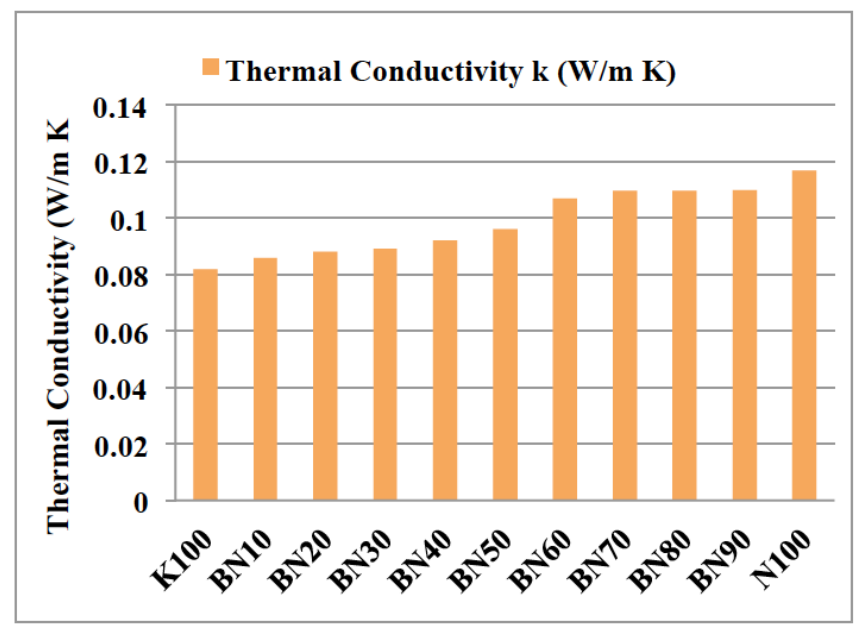

Figure 15: Thermal Conductivities of Kerosene and Kerosene/Neem Oil Blends.

Figures 16 and 17 indicate values of the heat capacities of the kerosene, kerosene/jatropha oil and kerosene/neem oil blends. Cengel and Turner [17] defined heat capacity of a material in terms of its density and specific heat, and it represents the heat 
storage capability of the material. It represents how much energy the material store per unit volume. This paper subscribed to this definition.

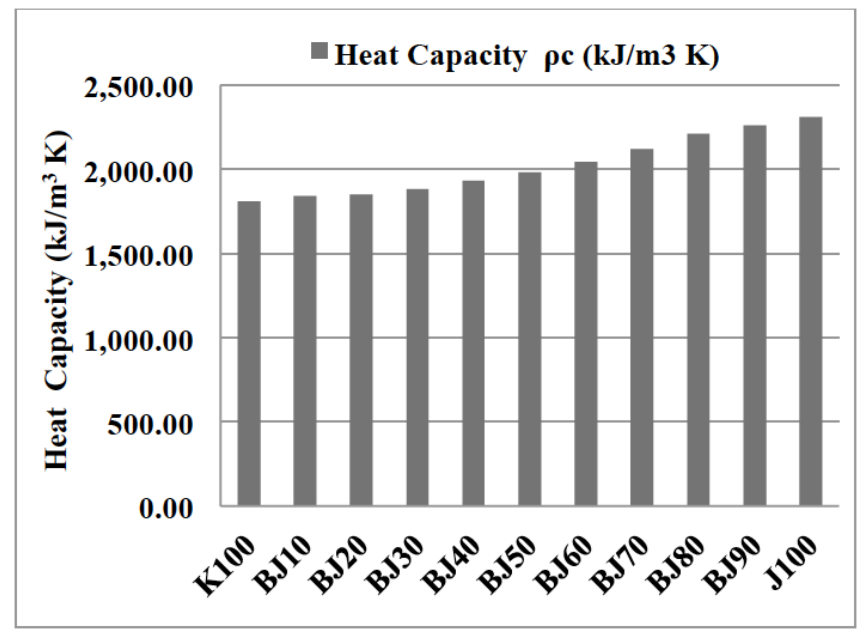

Figure 16: The Heat Capacities of Kerosene and Kerosene/Jatropha Oil Blends.

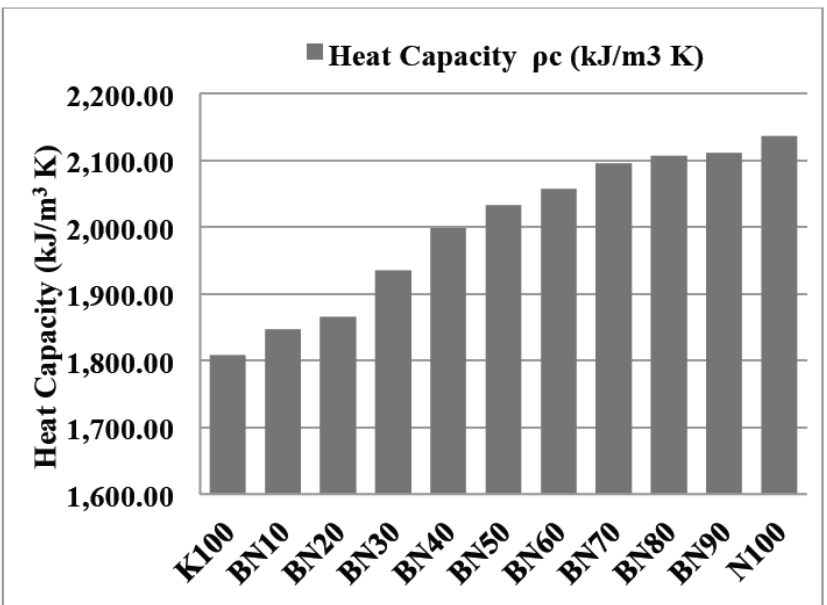

Figure 17: The Heat Capacities of Kerosene and Kerosene/Neem Oil Blends.

It can thus be noticed from Figures 6, 7, 14, 15, 16 and 17 that the two vegetable oils and their blends with kerosene have higher values of densities, thermal conductivities and heat capacities than those of the pure kerosene fuel. However, the energy contents (calorific values) of the raw oils and their blends with the kerosene sample were much lower than those of the kerosene fuel (Figures 12 and 13). High values of thermal conductivity and heat capacity of a fuel could make up for its low energy content, and thus make it suitable for use as fuel in cooking stoves. The specific heats of jatropha and neem oils at $2.688 \mathrm{~kJ} / \mathrm{kg} \mathrm{K}$ and $2.400 \mathrm{~kJ} / \mathrm{kg} \mathrm{K}$ respectively, which have been incorporated into the values of the heat capacities, were greater than the specific heat of the kerosene sample $(2.379 \mathrm{~kJ} / \mathrm{kg} \mathrm{K})$. Similarly, high values of densities and specific heats of the oils compared to the kerosene sample were indicative of the higher amounts of energy (heat capacities) the two oils store per unit volume with respect to the kerosene fuel. In addition, these three characteristics of the oils to some extent (i.e. densities, thermal conductivities, and heat capacities), made up for their low energy contents (calorific values) when compared to the kerosene sample, in terms of the ability of the oils to achieve faster cooking tasks when combusted in the liquid bio fuels cooking stoves.

\subsection{Chemical Property}

Figures 18 and 19 show the acid values of the kerosene, kerosene/jatropha oil and kerosene/neem oil blends. "Vegetable oils contain 1 to $5 \%$ free fatty acids" [7]. Acid value is an important index of physicochemical property of oil, which is used to indicate the quality, age, edibility and suitability of oil for use in industries such as paint (companies) [18]. The acid number values of $\mathrm{J} 100(1.2 \mathrm{mg} \mathrm{KOH} / \mathrm{g})$ and $\mathrm{N} 100$ (3.1 $\mathrm{mg} \mathrm{KOH} / \mathrm{g}$ ) vegetable oils did not meet the ASTM D6751 acid number standard specification $\{0.5 \mathrm{mg}$ $\mathrm{KOH} / \mathrm{g}$, and only $\mathrm{J} 100$ satisfied the DIN 51605 specification $\{2.0 \mathrm{mg} \mathrm{KOH} / \mathrm{g}\}$. Blending of the oils with K100 made it possible for all the kerosene/jatropha oil blends to meet the DIN 51605 specification, with only six kerosene/neem oil blends (BN10, BN20, BN30, $\mathrm{BN} 40, \mathrm{BN} 50$, and $\mathrm{BN60})\{0.5,0.79,1.03,1.48,1.74$, and 1.93$\} \mathrm{mg} \mathrm{KOH} / \mathrm{g}$ satisfying the requirement. Meanwhile among all the kerosene/oils blends, only BJ10 $(0.2 \mathrm{mg} \mathrm{KOH} / \mathrm{g}), B J 20(0.38 \mathrm{mg} \mathrm{KOH} / \mathrm{g})$, and BN10 $(0.5 \mathrm{mg} \mathrm{KOH} / \mathrm{g})$ met the ASTM D6751 standard acid number specification.

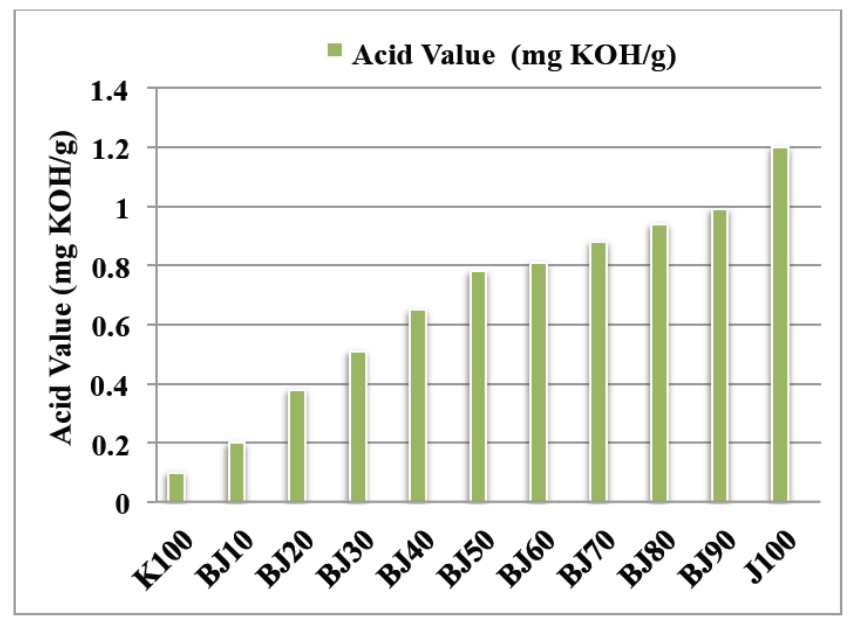

Figure 18: Acid Values of Kerosene and Kerosene/Jatropha Oil Blends. 


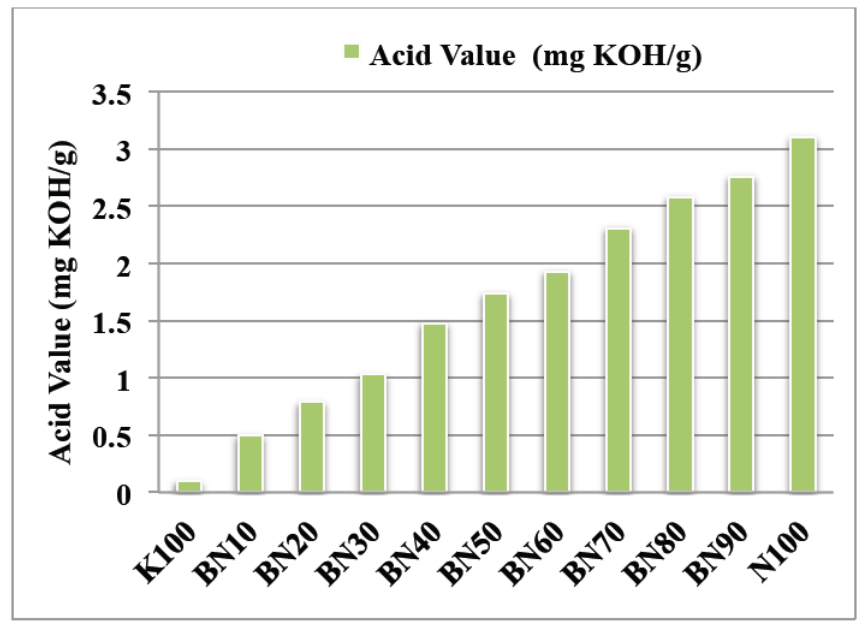

Figure 19: Acid Values of Kerosene and Kerosene/Neem Oil Blends.

The use of higher blends of the kerosene and jatropha or neem oils as fuels in the liquid bio fuels cooking stoves could lead to rapid corrosion of the fuel tanks, wick pipes, wick pipe holders, range burners and the flame holders. Therefore, corrosion resistant materials must be selected for these component parts, both in the design and development of the stoves.

\section{CONCLUSION}

The most significant aspect of this study was the realisation that there was no ASTM, EN, and ANP standard specification for the testing and characterisation of vegetable oils, which were to be used directly as fuels in engines, or in capillary fed wick lamps or cooking stoves. Similarly, there was no any standard specification for their blending with fossil solvents (diesel, kerosene, or gasoline). However, notwithstanding the absence of ASTM, EN, and ANP specifications for vegetable oils, research on the feasibility of using raw vegetable oils as fuels has not abated.

Meanwhile, the characterisation of neem and jatropha curcas oils and their blends with kerosene became necessary in order to obtain requisite data for the design process of liquid bio fuels cooking stoves, and to analyse performance and emission characteristics of the stoves when combusting these fuel oils blends. Accordingly, the standard test methods for Biodiesel B100 were used to characterise the raw vegetable oils of jatropha and neem, and their blends with kerosene in this research study.

The second significant aspect of this work was that almost all the test methods established by the three standard organisations mentioned above, especially on density and viscosity based the characterisation of fuels at $15^{\circ} \mathrm{C}$ and $38-40^{\circ} \mathrm{C}$ respectively. However, all the test fuels in this study were characterised at $30^{\circ} \mathrm{C}$. The reason being that $30^{\circ} \mathrm{C}$ was the average observed, but undocumented ambient temperature in the researchers' home kitchens. Accordingly, the properties of 21 test fuel samples made up of kerosene, jatropha oil, neem oil and the blends were experimentally determined at this temperature regime.

The two vegetable oils and their blends with kerosene have higher values of densities, thermal conductivities and heat capacities than those of the pure kerosene fuel. Meanwhile, the calorific values of the raw oils and their blends with the kerosene sample were much lower than that of the kerosene. High values of thermal conductivity and heat capacity of a fuel that has low calorific value, could contribute to its suitability for use as fuel in cooking stoves for cooking purposes and other domestic heat energy requirements. Similarly, high values of densities and specific heats of the oils compared to the kerosene sample were indicative of the higher amounts of energy (heat capacities) the two oils store per unit volume compared to the kerosene fuel. In addition, these three characteristics of the oils to some extent (i.e. densities, thermal conductivities, and heat capacities), made up for their lower calorific values when compared to the kerosene sample, in terms of the ability of the oils to achieve faster cooking tasks when combusted in the liquid bio fuels cooking stoves.

The use of higher blends of the kerosene and J100 or N100 oils as fuels in the liquid bio fuels cooking stoves could lead to rapid corrosion of the fuel tanks, wick pipes, wick pipe holders, range burners and the flame holders. Therefore corrosion resistant materials must be selected for these component parts, both in the design and development of the stoves.

\section{ACKNOWLEDGEMENT}

The authors sincerely express their gratitude to Dr. Nwanya Kenneth, the Principal Research Officer at NARICT - Zaria; Engineer Balarabe Musa, the Chief Technologist in the Department of Mechanical Engineering - Bayero University Kano; and Technologists M. Usman, U.I. Isa, M.G. Garba and B.U. Adam of the same institution, for their cooperation in the characterisation of the fuel/oils samples. 


\section{APPENDIX}

ANP $=$ The Brazilian Petroleum Standard Organisation; Agência Nacional do Petrôleo (National Agency of Petroleum)

ANSI = American National Standards Institute

ASTM = American Society for Testing and Materials

B = Blend of raw vegetable oil and fossil solvent

BJXX = Blend of raw jatropha curcas oil and kerosene. $X X$ refers to the volume percentage of the oil in the blend

$\mathrm{BNXX}=$ Bend of raw neem oil and kerosene. $\mathrm{XX}$ refers to the volume percentage of the oil in the blend

$\begin{array}{ll}\text { BS } & =\text { British Standard } \\ \text { DIN } & =\text { The German Petroleum Standard }\end{array}$ Organisation; Deutsche Institut für Normung

DOD = Department of Defence (USA)

EN = European Norms

FAME = Fatty Acid Methyl Ester

$\mathrm{HCV}=$ Higher Calorific Value

IP $\quad=$ Institute of Petroleum

$\mathrm{J}=\quad=$ Jatropha Oil

Jet $\mathrm{A}-1=$ International standard jet fuel (commercial $100 \%$ kerosene)

Jet $\mathrm{A}=$ Low grade Jet $\mathrm{A}-1$ and mostly used in the USA

JP-8 = Military jet fuel $(99.5 \%$ kerosene, $0.5 \%$ gasoline)

$\mathrm{J} 100=$ Raw undiluted jatropha oil

$\mathrm{K}=$ Kerosene

$\mathrm{kg} / \mathrm{m}^{3}=$ Kilogramme per cubic metre. SI unit of density

$\mathrm{kJ} / \mathrm{kg} \mathrm{K}=$ Kilojoules per kilogramme Kelvin. SI unit of specific heat

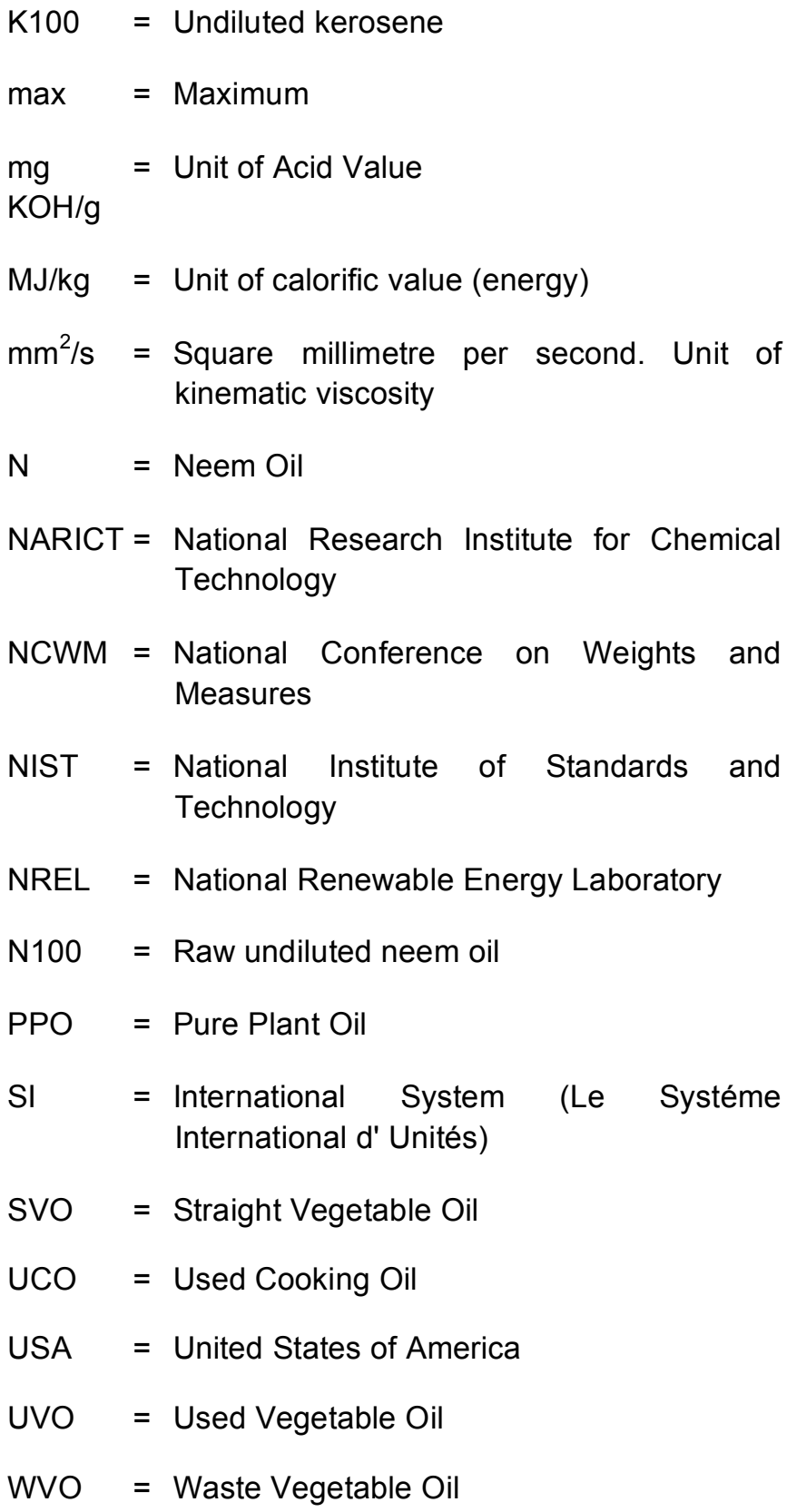

\section{REFERENCES}

[1] Biomass/Biofuel. Wikipedia. 2017 May 23; [cited 2017 May 23]. Available from: https://en.wikipedis.org/wiki/Biofuel

[2] National Renewable Energy Laboratory. Biodiesel Handling and Use Guide, $4^{\text {th }}$ Edn, 2008, Revised 2009. Tennessee: U.S. Department of Energy; 2009 [cited 2016 Jun 28]; 56pp. Available from: http://www.nrel.gov/transportation/ pdfs/43672.pdf

[3] National Conference on Weights and Measures. Uniform Engine Fuels and Automotive Lubricants Regulation, Handbook 130-2012, 1995. Revised 2008. NIST; 2008 [cited 2016 Jun 28]; 24pp. Available from: http://www.nist.gov/pml/ wmd/pubs/upload/section-IVg-12h130-final.pdf

[4] Blin J, Brunschwig C, Chapuis A, et al. Characteristics of Vegetable Oils for Use as Fuel in Stationary Diesel Engines Towards Specifications for a Standard in West Africa. Renewable and Sustainable Energy Reviews 2013; 22: 580597.

https://doi.org/10.1016/..rser.2013.02.018 
[5] Remmele E, Thuneke K. Pre - Standard DIN V51605 for Rapeseed Oil Fuel, 2007. In: Blin J, Brunschwig C, Chapuis A, et al. Characteristics of Vegetable Oils for Use as Fuel in Stationary Diesel Engines - Towards Specifications for a Standard in West Africa. Renewable and Sustainable Energy Reviews 2013; 22: 580-597.

https://doi.org/10.1016/j.rser.2013.02.018

[6] Sidibé SS, Blin J, Vaitilingom G, Azoumah Y. Use of Crude Filtered Vegetable Oil as a Fuel in Diesel Engines State of the Art: Literature Review. Renewable and Sustainable Energy Reviews 2010; 14: 2748-2759. https://doi.org/10.1016/j.rser.2010.06.018

[7] Srivastava A, Prasad R. Triglycerides-based Diesel Fuels. Renewable and Sustainable Energy Reviews 2000; 4: 111133.

https://doi.org/10.1016/S1364-0321(99)00013-1

[8] DIN 51605. Rapeseed Oil as Fuel, 2010 [cited 2016 Oct 5]. Available from: www.rjtc.de/downloads/rapeseed_oil_DIN_ 51605.pdf

[9] Okullo A, Temu AK, Ogwok P, Ntalikwa JW. PhysicoChemical Properties of Biodiesel from Jatropha and Castor Oils. International Journal of Renewable Energy Research 2012; 2(2): 47-52.

[10] IOR Energy. Product Specification Enersol kerosene, 2013 [cited 2016 Sep 24]. Available from: www.ior.com.au
[11] Cenex. Industry Standard Specification for Kerosene, 2016 [cited 2016 Sep 16]. Available from: www.cenex.com

[12] Soetaredjo FE, Budijanto GM, Prasetyo RI, Indraswati N Effects of Pre-Treatment Condition on the Yield and Quality of Neem Oil Obtained by Mechanical Pressing. Asian Research Publishing Network Journal of Engineering and Applied Sciences 2008; 3(5): 45-49.

[13] Adebowale KO, Adedire CO. Chemical Composition and Insecticidal Properties of the Underutilized Jatropha Curcas Seed Oil. African Journal of Biotechnology 2006; 5(10): 901906.

[14] Yadav A, Jha PC. A Case Study on Biofuel Stove Technology: Jatropha as a Biofuel. International Journal of Technology Enhancement and Emerging Engineering Research 2013; 1(2): 14-18.

[15] Nigerian Postal Service. Nigerian Postcode Directory, 3rd edn. Abuja 90001 FCT 2011.

[16] Government Notice. Legal Notice on Publication of 2006 Census Final Results, Abuja: Federal Republic of Nigeria Official Gazette 2009; 2(96): B1-42.

[17] Cengel YA, Turner RH. Fundamentals of Thermal-Fluid Sciences, New York: McGraw-Hill 2001; p. 609.

[18] Adinew B. Physico-Chemical Properties of Trichilia Emetica Seeds Oils and its Comparison with some Selected Oilseed Oils. Bulgarian Chemical Communications 2014; 46(2): 330333. 